\title{
MICROSTRUCTURE OF V-4Cr-4Ti FOLLOWING LOW TEMPERATURE
}

NEUTRON IRRADIATION

$$
\text { CONF-96/1125--2 }
$$

P. M. RICE, L. L. SNEAD, D. J. ALEXANDER, and S. J. ZINKLE Metals and Ceramics Division, Oak Ridge National Laboratory, P.O. Box 2008, Oak Ridge, TN 37831-6376

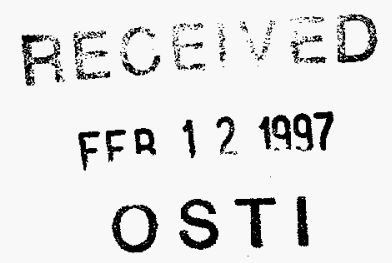

ABSTRACT

The $\mathrm{V}-4 \mathrm{Cr}-4 \mathrm{Ti}$ alloy displays excellent mechanical properties, including a ductile-to-brittle transition temperature (DBTT) below $-200^{\circ} \mathrm{C}$ in the unirradiated condition. Specimens of this alloy were fission neutron-irradiated in the High Flux Beam Reactor (HFBR) at Brookhaven National Laboratory (BNL) to a dose of $0.4 \mathrm{dpa}$ at temperatures from 100 to $275^{\circ} \mathrm{C}$. Mechanical testing showed significant irradiation hardening in the alloy which increased with increasing irradiation temperature. Charpy impact testing also showed a dramatic increase in the DBTT on the order of 200 to $350^{\circ} \mathrm{C}$. The mechanical property changes are correlated with preliminary results from the transmission electron microscopy (TEM) analysis of the defect microstructure resulting from the low-dose neutron irradiations. The TEM analysis of the irradiated material showed a nearly constant defect density of $\sim 1.6 \times 10^{23} \mathrm{~m}^{-3}$, with an average defect diameter of slightly greater than $3 \mathrm{~nm}$.

\section{INTRODUCTION}

The U.S. Fusion Materials program has identified V-4Cr-4Ti (wt\%) as a leading candidate material for structural applications in fusion reactors. The low activation, high thermal stress figure of merit (high thermal conductivity, moderate strength, and low coefficient of thermal expansion), and compatibility with liquid lithium have also made $\mathrm{V}$ alloys a promising candidate for low temperature, high-heat-flux in-vessel components for the International Thermonuclear Experimental Reactor (ITER).

Fast reactor experiments at temperatures in the range 425 to $600^{\circ} \mathrm{C}$ have shown $\mathrm{V}-4 \mathrm{Cr}-4 \mathrm{Ti}$ alloys to have promising resistance to radiation damage [1]. However, recent low-dose irradiations have found the alloys exhibit poor mechanical response in the low-temperature regime $\left(100\right.$ to $\left.275^{\circ} \mathrm{C}\right)[2,3]$. A summary of those mechanical property changes are presented below, followed by the preliminary results of a TEM investigation of the microstructure caused by the low-dose, low-temperature irradiations.

\section{EXPERIMENT}

Irradiations

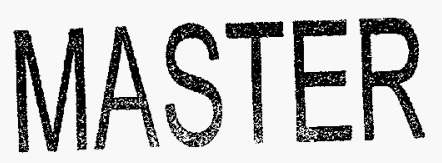

The material used in the experiment was taken from the $500 \mathrm{~kg}$ heat produced by Teledyne Wah Chang Albany (TWCA) for the U.S. Fusion Program (heat \#832665). This material contains approximately $300 \mathrm{ppm} \mathrm{O,} 85 \mathrm{ppm} \mathrm{N}$, and $80 \mathrm{ppm} \mathrm{C}$ (by weight) [4]. The plate was processed by TWCA and supplied in the form of 6.4-mm thick plate that had been annealed for $2 \mathrm{~h}$ at $1050^{\circ} \mathrm{C}$, in a vacuum better than $10^{-5}$ torr. Additional material was supplied as $\sim 40 \%$ Cold Worked sheet, 1 mm thick.

Subsize Charpy specimens were machined from the annealed plate. The specimens measured nominally $3.3 \times 3.3 \times 25.4 \mathrm{~mm}$ with a $30^{\circ}$ notch, $0.67 \mathrm{~mm}$ deep with $0.08 \mathrm{~mm}$ root radius. The notch was oriented for crack growth perpendicular to the rolling direction (L-T orientation). The specimens were annealed for $2 \mathrm{~h}$ at $1000^{\circ} \mathrm{C}$ in vacuum (better than $10^{-7}$ torr) after machining.

Small SS-3 sheet tensiles $(0.76 \times 1.52 \times 7.6 \mathrm{~mm}$ gage section) were machined from the cold-rolled sheet. These specimens were oriented in the longitudinal orientation (parallel to the rolling direction) and were also annealed for $2 \mathrm{~h}$ at $1000^{\circ} \mathrm{C}$ in vacuum (better than $10^{-7}$ torr) after machining. The final grain size of both the Charpy and SS-3 specimens was approximately $16 \mu \mathrm{m}$.
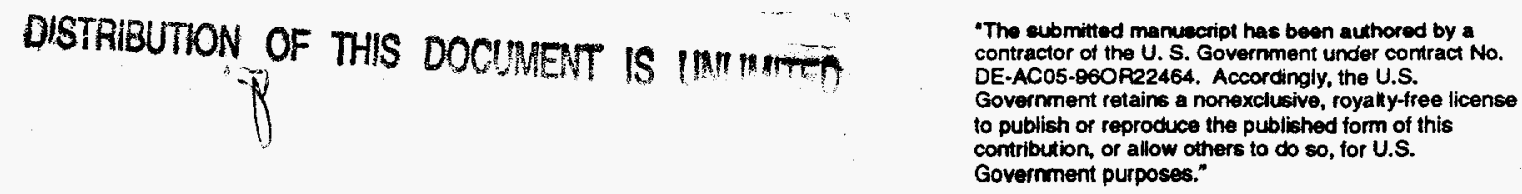

-The eubmitted manuscript has been authored by a contractor of the U.S. Government under contract No. DE-AC05-96OR22464. Accordingly, the U.S. Government retains a nonexclusive, royally-free license to publish of reproduce the published form of this contribution, of allow others to do so, for U.S. Government purposes." 
The irradiation capsules were designed for insertion into the core thimble position in the HFBR at Brookhaven National Laboratory. The experiment consisted of two separate capsules each containing 5 subcapsules. The capsules were purged with ultra-high-purity He, evacuated with a turbopump (three cycles), and finally filled with He to $10^{5} \mathrm{~Pa}$. The irradiation temperatures were varied from 110 to $275^{\circ} \mathrm{C}$ by varying the width of the gas gap for each subcapsule. Each subcapsule had at least one thermocouple that was attached to a Charpy specimen to monitor temperatures throughout the irradiation. Tensile specimens were not included in the $275^{\circ} \mathrm{C}$ subcapsule. Each of the two capsules was irradiated for $545 \mathrm{~h}$ ( 23 days) for estimated fast (E > $0.1 \mathrm{MeV}$ ) and thermal fluences of $8 \times 10^{24}$ and $3 \times 10^{24} \mathrm{n} / \mathrm{m}^{2}$ respectively. This fluence was calculated to produce about $0.1 \% \mathrm{Cr}$ and a damage level of $0.4 \mathrm{dpa}$.

The subsize Charpy specimens were tested in air on a pendulum machine modified for small specimens. The tensile specimens were all tested in air at room temperature, with a single test for each irradiation temperature. The tensile tests were conducted on a servohydraulic machine at an initial strain rate of $10^{-3} \mathrm{~s}^{-1}$. The load vs crosshead displacement test record was used to determine the tensile properties. Vickers hardness measurements were made at room temperature with a $500 \mathrm{~g}$ load using the grip section of SS-3 specimens prior to tensile testing; two specimens were tested in each condition, with at least $20 \mathrm{VHN}$ measurements on each specimen. The room temperature resistivity was measured prior to tensile testing, using standard 4-probe techniques (ASTM B 193-87, Standard Test Method for Resistivity of Electrical Conductor Materials, reapproved 1992). Three different tensile specimens were tested for each irradiation temperature.

\section{TEM Sample Preparation}

TEM specimens were prepared by sawing $\sim 0.25$-mm-thick slices off the ends of the Charpy specimens and punching $3 \mathrm{~mm}$ discs from the slices. Any burrs were ground off the discs before they were electrochemically thinned to electron transparency using a Tenupol twin jet polisher in a glove box in the hot cells at Oak Ridge National Laboratory. A sulfuric acid and methanol-based electrolyte was cooled to $\sim 10^{\circ} \mathrm{C}$ and a polishing current of $\sim 100 \mathrm{~mA}$ was used. The specimens all had an uneven oxide layer on their surfaces making defect detection difficult. All TEM micrographs were acquired utilizing a Philips CM12 TEM microscope operated at 120 $\mathrm{kV}$.

\section{RESULTS and DISCUSSION}

\section{$\underline{\text { Summary of Mechanical Test Results }}$}

A summary of the mechanical test results from the $\mathrm{V}-4 \mathrm{Cr}-4 \mathrm{Ti}$ specimens irradiated to 0.4 dpa are shown in Table 1 . The room-temperature yield strength, $\sigma_{y}$, essentially doubled at the lowest irradiation temperature and increased with increasing irradiation temperature, at least up to $235^{\circ} \mathrm{C}$. The tensile flow properties also changed significantly. A complete loss of work hardening capability and a uniform elongation of $<0.2 \%$ was observed for each irradiation temperature. The hardness, $\mathrm{H}$, was observed to increase $-54 \%$ at the lowest irradiation temperature. It also increased with increasing irradiation temperature. The fact that $\mathrm{H}$ increased between the $235^{\circ} \mathrm{C}$ irradiation and the one at $275^{\circ} \mathrm{C}$ is strong evidence that the $\sigma_{y}$ would also have shown an increase at $275^{\circ} \mathrm{C}$ as well. The DBTT increased nearly 200 degrees at the low irradiation temperature and after irradiation at $235^{\circ} \mathrm{C}$ it has changed by nearly 350 degrees. The fact that there is little change between the irradiation temperatures of 235 and $275^{\circ} \mathrm{C}$ indicate that the DBTT shift seemed to have reached saturation. At the lowest irradiation temperature the resistivity, $\rho_{e}$, was only slightly increased over its unirradiated value. However, as the irradiation temperature increased $\rho_{\mathrm{e}}$ decreased such that at $235^{\circ} \mathrm{C}$, it was actually less than it was in the unirradiated condition.

The increase in $\sigma_{\mathrm{y}}, \mathrm{H}$ and DBTT with irradiation temperature has two likely explanations. Either the defect density increases with irradiation temperature, or the strength of the defect clusters as dislocation barriers increases with irradiation temperature. The decrease in $\rho_{e}$ with irradiation temperature supports the latter process, suggesting an increase in barrier strength with increasing temperature due to segregation of interstitial solute atoms (for $\mathrm{T}>140^{\circ} \mathrm{C}, \mathrm{O}$ and $\mathrm{C}$; and for $\mathrm{T}>$ $225^{\circ} \mathrm{C}, \mathrm{N}$ ) [5]. This effect could strengthen the defect clusters while while reducing $\rho_{\mathrm{e}}$ due to electron scattering in the matrix. 


\section{DISCLAIMER}

Portions of this document may be illegible in electronic image products. Images are produced from the best available original document. 
Table I: Summary of Mechanical Test Results

\begin{tabular}{|c|c|c|c|c|c|}
\hline Measured & Unirradiated & \multicolumn{4}{|c|}{ Irradiation Temperature $\left({ }^{\circ} \mathrm{C}\right)$} \\
\hline Property & Condition & 110 & 205 & 235 & 275 \\
\hline $\begin{array}{c}\text { Yield Strength } \\
\sigma_{\mathbf{y}}(\mathbf{M P a}) \\
\left(10^{-3} \mathrm{~s}^{-1}\right)\end{array}$ & 326.5 & 640 & 705 & 765 & \\
\hline $\begin{array}{l}\text { Hardness } \\
\text { H (VHN) } \\
(500 \mathrm{~g})\end{array}$ & $133 \pm 1$ & 205 & 226 & 232 & 250 \\
\hline $\begin{array}{l}\text { 1/3 Charpy } \\
\left.\text { DBTT ( }{ }^{\circ} \mathrm{C}\right) \\
\text { (Mach. Notch) }\end{array}$ & -190 & -14 & 85 & 141 & 139 \\
\hline $\begin{array}{c}\text { Resistivity } \\
\rho_{\mathrm{e}}(\mathbf{n} \Omega-\mathbf{m})\end{array}$ & $280 \pm .7$ & 289 & 282 & 275.5 & \\
\hline
\end{tabular}

\section{Preliminary TEM Results}

To differentiate between the possible physical mechanisms responsible for the extensive hardening and embrittlement observed in the low-dose, low-temperature irradiation experiments, the defect microstructure was investigated using conventional TEM imaging techniques. To determine foil thicknesses the foils were tilted to strong two-beam conditions exactly at the Bragg condition such that $g=(110)$ and $s=0$. Regions approximately one extinction distance thick were then identified for use in the analysis. Bright-field/weak-beam dark-field image pairs were acquired over a range of magnifications to allow for the determination of defect density measurements and defect size distributions.

The extinction distance for $g=(110)$ in the vanadium alloy, $\xi_{110}^{V}$, was calculated by correcting for the difference in the volume of the unit cell, $\mathrm{V}$, the difference in the scattering amplitude, $f$, and a correction factor for the difference in electron energy, $v$, with respect to the extinction distance for $g=(110)$ in iron which is listed in reference 6.

$$
\xi_{110}^{V}(120 \mathrm{keV})=\left(\frac{V_{V}}{V_{F e}}\right)\left(\frac{f_{F e}}{f_{V}}\right)\left(\frac{v_{120}}{v_{100}}\right) \xi_{110}(100 \mathrm{keV})
$$

Using a volume correction of 1.177 , a scattering amplitude correction of $\sim 1.1$, and an energy correction of 1.068, the above equation gives the extinction distance for $120 \mathrm{keV}$ electrons in the $\mathrm{g}=110$ Bragg reflection in vanadium to be $\sim 37.5 \mathrm{~nm}$.

Defect densities were measured using bright-field images acquired with $g=(220)$ or $(330)$ to reduce the contrast from the defect clusters; a typical example is shown in figure 1 . The number of identifiable defects in a boxed area of $5 \mathrm{~cm} \mathrm{x} 5 \mathrm{~cm}$ at a print magnification of $250 \mathrm{kx}$ in a region approximately $40 \mathrm{~nm}$ thick were counted. A minimum of two boxes were counted and averaged for each condition. The number should be considered a lower limit since most of the smaller defects were not visible in such images. Since $50 \%$ of a $/ 2<111>$ dislocation loops are invisible for these diffraction vectors the plotted values which appear in figure 2 are twice the counted averages.

Within the fairly large uncertainty associated with such measurements, the defect densities are essentially constant across the irradiation temperature range from 100 to $275^{\circ} \mathrm{C}$. The large differences in the room temperature mechanical properties at the different irradiation temperatures is clearly not due to a difference in visible defect densities. 


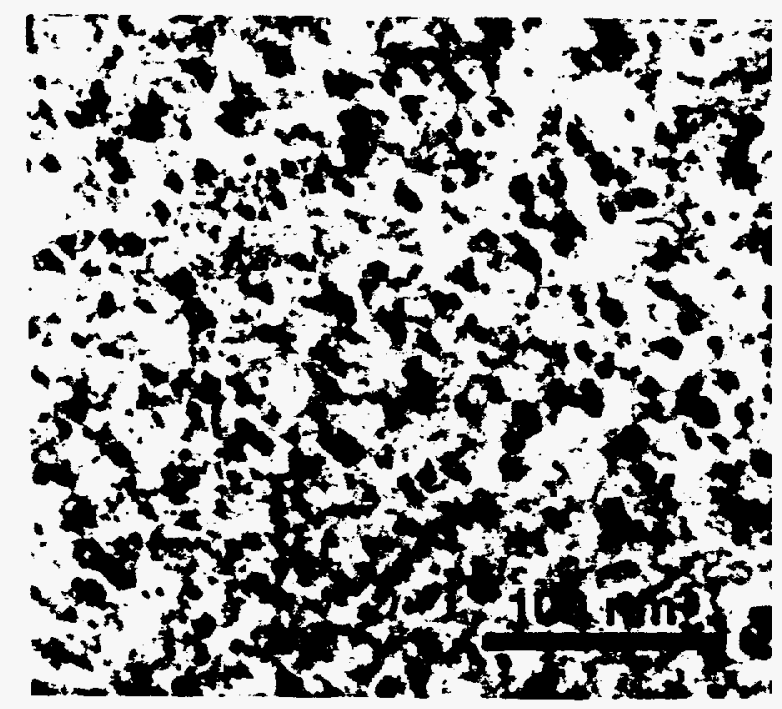

Figure 1. Typical BF image of $\mathrm{V}-4 \mathrm{Cr}-4 \mathrm{Ti}$ irradiated to $0.4 \mathrm{dpa}$ at $275^{\circ} \mathrm{C}$. $(\mathrm{g}=220)$

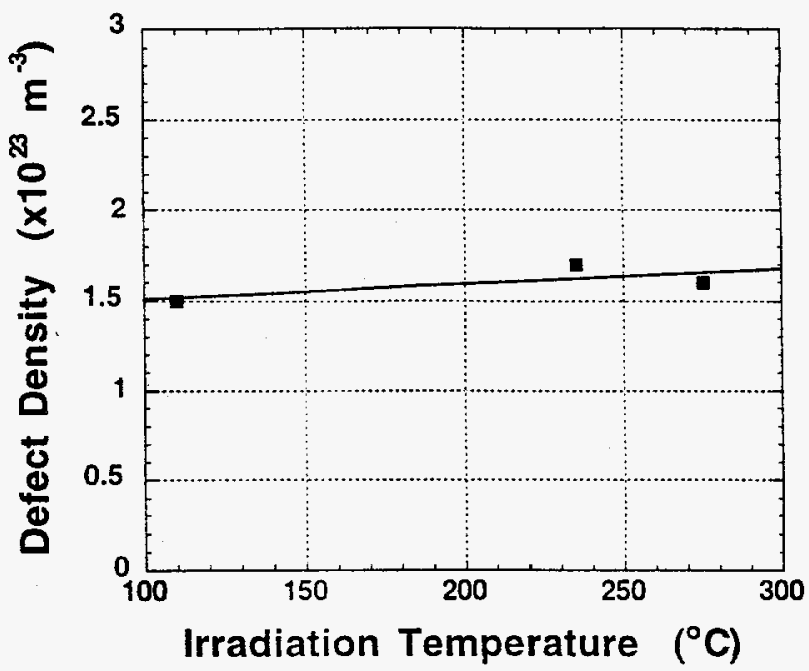

Figure 2. Plot of defect density as a function of the irradiation temperature.

The defect size distributions were measured from weak-beam dark-field (WBDF) images acquired using $(\mathrm{g}, 5 \mathrm{~g}) \mathrm{g}=(110)$ diffracting conditions, similar to that shown in figure 3 , at the same regions used in the defect density measurements. In this case, images with print magnifications of $500 \mathrm{kx}$ were used and measurements of all identifiable defects within a region were measured to the nearest $\mathrm{nm}$ and tabulated before moving to the next region. This process was continued until at least 100 defects had been measured for specimens irradiated at the lowest and highest temperatures.

A plot of the defect size distributions is shown in figure 4 . There is a statistically insignificant difference in defect diameters between the low and high irradiation temperature, with the average defect diameters being 3.1 and $3.7 \mathrm{~nm}$ respectively. The specimens had a fairly thick, uneven oxide layer on them due to the polishing precedures which made identifying defects and measuring diameters in the weak-beam condition difficult. These values should be considered preliminary and measurements on appropriately polished specimens are expected to show an even greater fraction of the defects with diameters $<2 \mathrm{~nm}$. The statistically insignificant difference in defect sizes across the temperature range makes it unlikely that the difference in room temperature mechanical properties as a function of irradiation temperature could be explained by defect size effects alone.

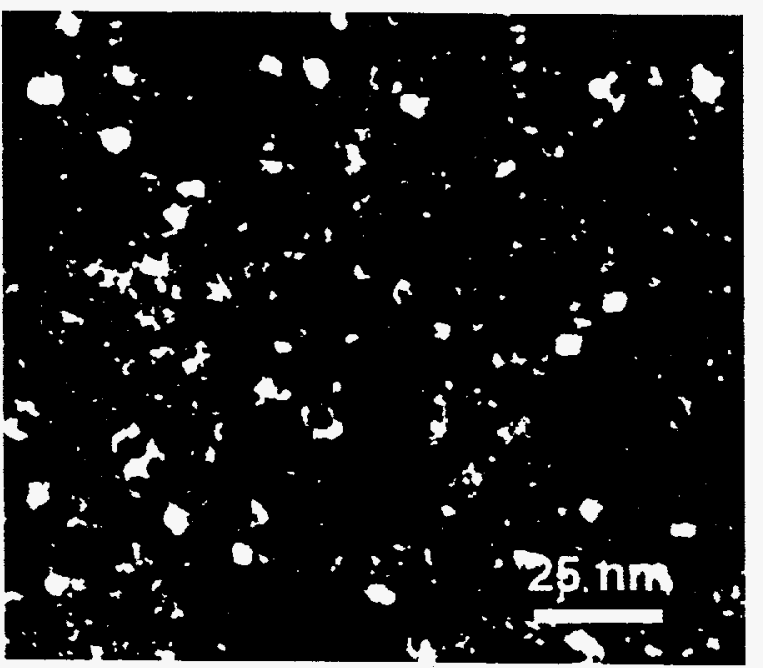

Figure 3. Typical WBDF image of $\mathrm{V}-4 \mathrm{Cr}-4 \mathrm{Ti}$ irradiated to $0.4 \mathrm{dpa}$ at $275^{\circ} \mathrm{C}$. $(\mathrm{g}, 5 \mathrm{~g}, \mathrm{~g}=110)$

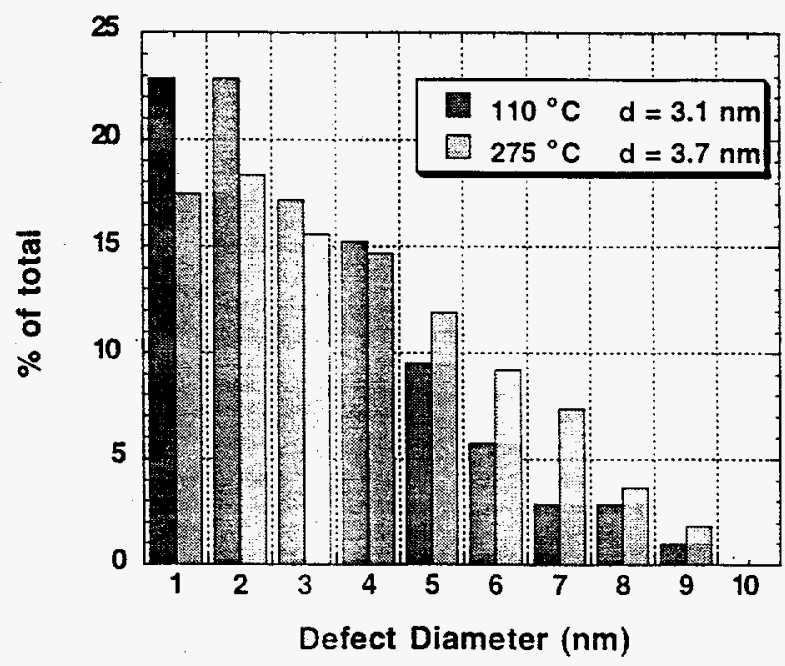

Figure 4. Plot of the defect size distributions for specimens irradiated at 110 and $275^{\circ} \mathrm{C}$ 
It is known that defect clusters and small loops like those described above act as barriers to dislocation motion and thereby harden or strengthen the material. The dislocation barrier strength, $\alpha$, can be estimated by using the relation [7]

$$
\Delta \sigma_{y}=3 \alpha \mu b \sqrt{N d}
$$

$$
\text { where } \begin{aligned}
& \Delta \sigma_{y}=\text { change in yield strength } \\
& \mu \underline{\underline{ }} \text { shear modulus } \\
& \mathrm{b}=\text { Burgers vector } \\
& \mathrm{N}=\text { density of defect clusters } \\
& \mathrm{d}=\text { defect diameter }
\end{aligned}
$$

$\frac{110^{\circ}}{314 \mathrm{MPa}}$
$46 \mathrm{GPa}$
$0.23 \mathrm{~nm}$
$1.5 \times 10^{23} \mathrm{~m}^{-3}$
$3.1 \mathrm{~nm}$

Using the measured values for the specimen irradiated at $110^{\circ} \mathrm{C}$, shown on the right above Eqn. 2 gives the dislocation barrier strength of the defect clusters to be 0.4 . While this is slightly above the accepted value for small loops of $\sim 0.2$, it is well below the maximum value for impenetrable obstacles of $\alpha=1$ [8]. This leads us to believe that the values for defect densities reported in this paper are reasonable. Improved measurements from better specimens will likely show increased $\mathrm{N}$, and slightly decreased $\mathrm{d}$, and thus should slightly decrease the measured value of $\alpha$.

While the change in yield strength for the specimens irradiated at $275^{\circ} \mathrm{C}$ was not measured, it is clear from the hardness measurements that it should be significantly larger than that measured for specimens irradiated at 110 to $235^{\circ} \mathrm{C}$ (Table 1). The insignificant changes in $\mathrm{N}$ and $\mathrm{d}$ observed for the higher temperature irradiation would not explain this difference. Thus equation (2) would require a higher value of $\alpha$ for the defects created at higher temperature. It seems reasonable to speculate that the segregation of solute atoms may be primarily responsible for the strengthening of the defect clusters. Oxygen and carbon would migrate in vanadium at $\sim 140^{\circ} \mathrm{C}$ during the onemonth HFBR irradiation [5], and thus may be responsible for the hardening between 110 and $235^{\circ} \mathrm{C}$. Nitrogen would become mobile in vanadium above $-225^{\circ} \mathrm{C}$ during the HFBR irradiation [5] and thus may be responsible for the increase in hardness between 235 and $275^{\circ} \mathrm{C}$. This hypothesis is supported by the measured change in resistivity. The increase in resistivity due to irradiation at $110^{\circ} \mathrm{C}$ can be attributed to scattering from defect clusters alone, since the interstitial solute atoms are immobile at this temperature. At the higher temperatures the resistivity decreases as the solute atoms are removed from the matrix and concentrated at the defect clusters.

There also appears to be some evidence for the presence of very small cavities in the specimen irradiated at $275^{\circ} \mathrm{C}$. Under- and over-focused images taken at high magnification show a very high density $\left(>10^{24} \mathrm{~m}^{-3}\right)$ of what appear to be cavities with diameters $\leq 1 \mathrm{~nm}$. Figure 5 shows one of the under-focused images acquired near the edge of the foil. Future experiments will more thoroughly characterize the distribution of these smaller cavities as a function of irradiation temperature. Figure 6 shows a grain boundary region irradiated at $110^{\circ} \mathrm{C}$. There is no evidence at any of the temperatures of a denuded zone at the grain boundaries or around the large $\mathrm{Ti}(\mathrm{O}, \mathrm{C}, \mathrm{N})$ precipitates.

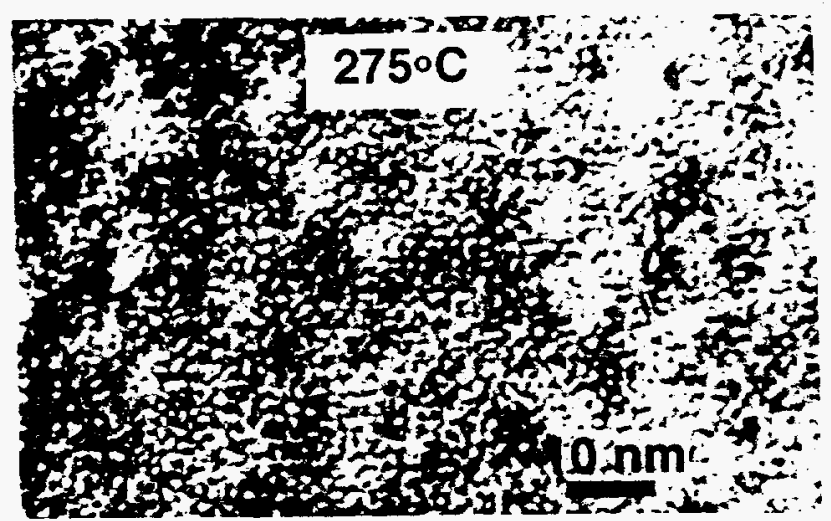

Figure 5. Under-focused image showing possible cavities as bright spots.

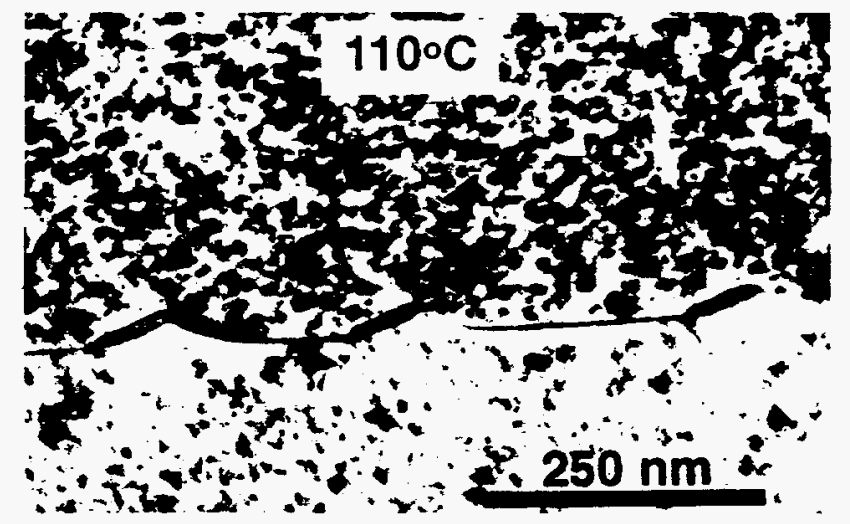

Figure 6. Image of a grain boundary region showing no denuded zone at $110^{\circ} \mathrm{C}$. 


\section{CONCLUSIONS}

It is clear from these results that irradiation to $0.4 \mathrm{dpa}$ at low temperatures $\left(100\right.$ to $\left.275^{\circ} \mathrm{C}\right)$ causes significant changes in the mechanical properties of $\mathrm{V}-4 \mathrm{Cr}-4 \mathrm{Ti}$. The observed embrittlement is directly related to the radiation hardening resulting from a high density of small dislocation loops. Specimens across the entire range of irradiation temperatures showed a similar loop density of $\sim 1.6 \times 10^{23} \mathrm{~m}^{-3}$. The increase in yield strength, hardness and DBTT with increases in irradiation temperature is not due to changes in the visible defect cluster density or size, and thus it is probably due to the segregation of solute atoms to the defect clusters. This hypothesis is further supported by the decrease in resistivity with increasing irradiation temperature.

These results indicate that the minimum operating temperature for $\mathrm{V}-4 \mathrm{Cr}-4 \mathrm{Ti}$ in fusion energy systems should be $>275^{\circ} \mathrm{C}$. The range of temperatures over which significant embrittlement occurs needs to be determined, and further irradiation experiments at 330 and $400^{\circ} \mathrm{C}$ are being carried out. We are also pursuing improvements to the polishing procedure for TEM specimens in order to complete a more thorough investigation of the existence of cavities throughout the temperature range.

\section{ACKNOWLEDGMENTS}

The authors would like to thank Scott Eatherly and Jeff Baily for their efforts in constructing and irradiating the capsules. Also, the efforts of Joe O'Conner, Guy Hartsough and Joel Erraute in the research coordination group at the HFBR are greatly appreciated. This research was sponsored by the Office of Fusion Energy Sciences, U.S. Department of Energy, under contract DE-AC05-96OR22464 with Lockheed Martin Energy Research Corp., and was conducted utilizing the Shared Research Equipment User Program facilities at Oak Ridge National Laboratory.

\section{REFERENCES}

1. B. A. Loomis et al,. J. Nuclear Materials, 212-215, 799 (1994).

2. D.J. Alexander, L.L. Snead, S.J. Zinkle, A.N. Gubbi, A.F. Rowcliffe, and E.E. Bloom, in Fusion Materials Semiannual Progress Report for Period Ending June 30, 1996, DOE/ER0313/20, p. 87, (1996).

3. D.J. Alexander, L.L. Snead, S.J. Zinkle, A.N. Gubbi, A.F. Rowcliffe, W.S. Eatherly, and E.E. Bloom, in Effects of Radiation on Materials: 18th International Symposium, ASTM STP 1325, edited by R.K. Nanstad, M.L. Hamilton, F.A. Garner, and A. S. Kumar, American Society for Testing and Materials, (1997) in press.

4. M.L. Grossbeck, et al., in Fusion Materials Semiannual Progress Report for Period Ending December 31, 1995, DOE/ER-0313/18, p. 183, (1995).

5. J.T. Staney et al., Acta Met., 20, 191 (1972).

6. P. Hirsch, A. Howie, R Nicholson, D.W. Pashley, and M. J. Whelan, Electron Microscopy of Thin Crystals, 2nd ed., Krieger Publishing Company, Malabar, Florida, pp. 509-511 (1977).

7. S. Kojima, S. J. Zinkle, and H.L. Heinisch, J. Nuclear Materials, 179-181, 982 (1991).

8. A. L. Belmont, Jr., in Strength of Metals and Alloys, Proc. of 2nd Int. Conf., ASM International, Metals Park, OH, p. 693 (1973). 